\title{
LITERATURA SURDA: ANÁLISE DE UM CONTO INFANTIL À LUZ DA TRADUÇÃO INTERCULTURAL E INTERMODAL
}

\author{
Lyvia de Araújo Cruz ${ }^{1}$ \\ 1'Instituto Federal de Educação, Ciência e Tecnologia do Ceará, Camocim, \\ Ceará, Brasil
}

Michelle Arrais Guedes 2

2Instituto Federal de Educação, Ciência e Tecnologia do Ceará, Sobral, Ceará, Brasil

Andréa Michiles Lemos ${ }^{3}$

${ }^{3}$ Instituto Federal de Educação, Ciência e Tecnologia do Ceará, Fortaleza,

Ceará, Brasil

Resumo: Este artigo insere-se no campo da Literatura Surda em sua interface com os Estudos da Tradução e com os Estudos Culturais. Neste trabalho apresentamos uma análise da tradução (português-Libras) do conto literário "O sanduíche da Maricota" de Avelino Guedes. O nosso objetivo consiste em analisar a tradução do conto, comparando-a a uma nova proposta tradutória desenvolvida por nós, proposta esta que considera as estratégias de uma tradução intermodal e intercultural. Nesta pesquisa de cunho qualitativo e descritivo, recorremos ao procedimento do estudo de caso. Quanto aos pressupostos teóricos, lançamos mão das noções de Literatura Surda apresentadas por Karnopp, Sutton-Spence e Silveira e trabalhamos com os aportes teóricos da Tradução Intermodal e Intercultural trazidos por Segala e Valente. Existem poucas pesquisas sobre a tradução literária em Libras. Dessa forma, faz-se necessário mais discussões acerca dos trabalhos existentes, para que possamos pensar novas estratégias para a produção de novos conhecimentos sobre o processo de tradução literária para surdos. A contribuição deste artigo é compartilhar conhecimentos acerca da tradução intermodal e intercultural para surdos, assim como 
colaborar com o processo de qualificação dos profissionais de tradução voltados ao âmbito literário.

Palavra-chave: Tradução Intermodal e Intercultural; Literatura Surda; Língua de Sinais; Cultura Surda

\title{
DEAF LITERATURE: ANALYSIS OF A CHILDREN'S TALE ACCORDING TO INTERCULTURAL AND INTERMODAL TRANSLATION
}

\begin{abstract}
This article is part of the field of Deaf Literature in its interface with Translation Studies and Cultural Studies. In this work we present an analysis of the translation (Portuguese-Libras) of the literary short story "O sanduíche da Maricota" by Avelino Guedes. Our aim is to analyze the translation of the short story, comparing it to a new translation developed by us, a proposal that considers the strategies of an intermodal and intercultural translation. In this qualitative and descriptive research, we used the case study procedure. Regarding the theoretical assumptions, we used the concepts of Deaf Literature presented by Karnopp, SuttonSpence and Silveira, and we worked with the theoretical contributions of Intermodal and Intercultural Translation brought by Segala and Valente. There is little research on literary translation in Libras. Thus, more discussion about the existing works is needed, so that we can think of new strategies for the production of new knowledge about the literary translation process for the deaf. The contribution of this article is to share knowledge about intermodal and intercultural translation for the deaf, as well as collaborating with the qualification process of the translation professionals focused on the literary field.
\end{abstract}

Keywords: Intermodal and Intercultural Translation; Deaf Literature; Sign language; Deaf Culture

\section{Introdução}

Neste artigo apresentamos uma análise da tradução do conto literário "O sanduíche da Maricota" que foi traduzido do português para Libras. São objetivos do trabalho: analisar a tradução português-Libras encontrada deste conto; buscar entender como 
essa tradução pode ser mais adequada, comparando-a a uma nova proposta de tradução, realizada pelas autoras deste artigo; buscar estratégias de 'melhoramento' para a tradução do conto.

A Língua Brasileira de Sinais (Libras), como qualquer língua, expressa emoção, sentimentos, significados, sentidos e tem poder de comunicação, o que a diferencia de outras línguas é a sua modalidade de realização. Ao contrastar as culturas surda e ouvinte, vemos que os ouvintes sentem emoção ao escutar os sons e seus diferentes efeitos, já os surdos sentem emoção ao perceber o mundo visualmente. Os surdos têm uma língua própria e essa língua, que é gestual-visual, possui gramática própria. Portanto, como qualquer língua, possui uma estrutura de funcionamento com a sua fonologia, morfologia, sintaxe, semântica, pragmática, o uso de expressões idiomáticas, regionalismos, gírias, tal qual como há nas línguas orais. Sobre isto, Quadros e Karnopp acrescentam:

As línguas de sinais são, portanto, consideradas pela linguística como línguas naturais ou como um sistema linguístico legítimo e não como um problema do surdo ou como uma patologia da linguagem. Stokoe, em 1960, percebeu e comprovou que a língua de sinais atendia a todos os critérios linguísticos de uma língua genuína, no léxico, na sintaxe e na capacidade de gerar uma quantidade infinita de sentenças. (Quadros e Karnopp 30).

As comunidades surdas usam a língua de sinais a partir da sua experiência visual, percebem as formas, imagens, coloridos, características de pessoas, animais, ações, através de suas memórias visuais. Percebem e entendem o mundo pela visão. Para Strobel, a experiência visual é o que constitui os surdos enquanto indivíduos:

A experiência visual significa a utilização da visão como meio de comunicação. Desta experiência visual surge a cultura surda representada pela língua de sinais, pelo modo

Cad. Trad., Florianópolis, v. 41, $\mathbf{n}^{0}$ esp. 2, p. 223-249, ago/dez, 2021. 225 
diferente de ser, de se expressar, de conhecer o mundo, e de entrar nas artes, conhecimento científico e acadêmico. (Strobel 45).

Os povos surdos vivenciam a sua cultura a partir de um referencial visual e estabelecem artefatos culturais, que podem ser: linguístico, familiar, literário, da vida social e esportiva, das artes visuais, da política. A “cultura surda é o jeito pelo qual o sujeito surdo entende o mundo e o modifica a fim de torná-lo acessível e habitável, ajustando-o com as suas percepções visuais, que contribuem para a definição das identidades surdas" (Strobel 22). Ainda de acordo com Strobel:

\begin{abstract}
Quando pronunciamos "povo surdo", estamos nos referindo aos sujeitos surdos que não habitam no mesmo local, mas que estão ligados por uma origem, por um código ético de formação visual, independente do grau de evolução linguística, tais como a língua de sinais, a cultura surda e quaisquer outros laços. (Strobel 38).
\end{abstract}

Os surdos têm o direito a ter uma compreensão visual de qualquer conto ou história em sua primeira língua, com adaptação do vídeo em Libras. A maioria dos ouvintes tem facilidade em comprar livros traduzidos de uma língua estrangeira para o português. Mas, como se traduz livros para outra modalidade de língua pertencente a uma minoria linguística? Esse é o problema enfrentado pelos surdos, como ter uma tradução para a comunidade surda, com acesso à Libras.

Para traduzir e interpretar qualquer língua de sinais, é importante conhecer a cultura surda, pois este conhecimento ajuda no desenvolvimento do trabalho com o surdo em diversas áreas, tendo em vista que é o referencial visual que engloba a identidade surda em seus vários tipos. A cultura surda é intrínseca à literatura surda. No que se refere ao escopo da literatura surda, sabemos

Cad. Trad., Florianópolis, v. 41, $\mathrm{n}^{0}$ esp. 2, p. 223-249, ago/dez, 2021. 226 
que existem três grandes eixos: o da tradução, o da adaptação e o da criação.

Entendemos que a literatura traduzida é a que pode envolver maiores problemáticas, porque trabalha com culturas diferentes. Podem surgir dificuldades, por parte do tradutor, em expressar-se na modalidade gestual-visual e na estrutura gramatical da língua de sinais. A literatura é marcada fortemente por uma cultura ouvinte, os livros são escritos para ouvintes, essa literatura passa a ser traduzida para as comunidades surdas para que elas tenham acesso à cultura ouvinte ou a literatura em geral.

Percebe-se que, em relação à literatura surda, ainda há um grande caminho a ser percorrido. Nesse sentido, observamos que ainda são incipientes as publicações. Encontramos problemas nas traduções em Libras que levam a não compreensão efetiva, falhas como: falta de estrutura gramatical da Libras e não presença de emoção na história, não contribuem para que os variados públicos surdos gostem da literatura em geral.

\section{Literatura surda}

As produções surdas existem desde quando um surdo encontra o seu outro semelhante. As línguas de sinais foram se desenvolvendo e com elas os surdos foram se expressando e produzindo cultura: histórias surdas, piadas, narrativas autobiográficas, lendas, etc. são transmitidas de geração em geração através das mãos destes que têm a experiência visual como marca de sua identidade, porém havia muitas perdas nessa trajetória, visto que não existiam recursos tecnológicos para captar tridimensionalmente uma língua de natureza gestual-visual.

Somente com a tecnologia é que tais produções se difundiram e ganharam notoriedade na comunidade surda, tendo repercussões positivas no fortalecimento da identidade surda e no reconhecimento do ser surdo em uma cultura visual capaz de dar conta de sua singularidade. É a partir daí, que a Literatura Surda encontra

Cad. Trad., Florianópolis, v. 41, $\mathbf{n}^{0}$ esp. 2, p. 223-249, ago/dez, 2021. 227 
terreno fértil para o seu desenvolvimento e difusão. Entretanto, então, o que é Literatura Surda?

Literatura Surda é a produção literária dos povos surdos, que expressa as culturas e identidades dos sujeitos surdos, ou seja, o mundo através de sua cosmovisão. Karnopp e Machado, citados por Rosa (32) trazem à baila algumas questões importantes sobre a Literatura Surda:

[...] utilizamos a expressão "literatura surda" para histórias que tem as línguas de sinais, a questão da identidade e cultura surda presente nos textos e imagens de livros de literatura infantil. A literatura surda está relacionada com a cultura surda. A literatura da cultura surda, contada na língua de sinais de determinada comunidade linguística, é constituída pelas histórias produzidas em língua de sinais pelas pessoas surdas, pelas histórias de vidas, que são constantemente relatadas, pelos contos, pelas lendas, fábulas, piadas, poemas sinalizados, anedotas, jogos de linguagem e muito mais. O material, em geral, reconta as experiências das pessoas surdas, no que diz respeito, direta ou indiretamente, à relação entre as pessoas surdas e ouvintes, que são narradas como relações conflituosas, benevolentes, de aceitação ou de opressão. (Karnopp e Machado 3).

As sociedades cultivam uma tradição histórica, vivenciada a cada geração, que é a contação de histórias, tradição que passa de pai para filho, o que permite a transmissão e a expressão do pensamento imaginário. Contudo, e as crianças surdas? Como elas conseguem alcançar esse pensamento imaginário? Na maioria dos casos, a criança surda é filha de pais ouvintes e tem uma língua e cultura diferentes dos pais. As crianças só conseguirão se expressar com a língua gestual e se comunicar com os seus pais ouvintes através da língua de sinais se houver uma inserção dos pais nessa comunicação.

Morgado (157) cita a importância da escola para a origem da língua gestual e a partir disso o fortalecimento dos costumes da

Cad. Trad., Florianópolis, v. 41, $\mathbf{n}^{0}$ esp. 2, p. 223-249, ago/dez, 2021. 228 
contação de histórias através dessa língua, porém durante muito tempo foi obrigado, nas escolas, o uso oral do português e proibido a utilização da língua de sinais.

Como se sabe, língua gestual só nasce quando há mais do que um surdo e a escola é, regra geral, o seu ponto de encontro. Assim, em todos os países onde existe uma língua gestual, é possível remeter a sua origem para a escola. À medida que as línguas gestuais se foram desenvolvendo, nasceram as primeiras histórias em mímica, as primeiras imitações e por aí afora, mas sempre dentro dos internatos, sempre às escondidas dos supervisores oralistas. $\mathrm{O}$ facto de a língua gestual ter sido proibida fez com que os surdos sentissem maior necessidade de sua língua. Por isso, as histórias contadas às escondidas foram ficando cada vez mais fortes e estruturadas. (Morgado 157).

Karnopp e Silveira (19) falam que embora

a tradição de contar histórias oral e presencialmente tenha diminuído através dos tempos, e as narrativas escritas tenham ampliado o campo de atuação, o maior obstáculo é a impossibilidade de escutar as narrativas, como eram feitas pelos contadores, pois não podem transmitir os efeitos que devem ter dado vida às histórias. (Karnopp e Silveira 19).

Diferentemente das crianças ouvintes, que utilizam a comunicação oral, as crianças surdas usam a língua de sinais, elas falam pelas mãos e "escutam" pelos olhos, numa comunicação visual. Os estudos de Quadros e Karnopp (2007) reafirmam a pesquisa do linguista americano Stokoe, e comprovam que a língua de sinais é um sistema linguístico com estrutura gramatical, assim como as línguas orais. As crianças surdas precisam entender, pensar e expressar na sua primeira língua, a língua de sinais, pois elas têm

Cad. Trad., Florianópolis, v. 41, $\mathbf{n}^{0}$ esp. 2, p. 223-249, ago/dez, 2021. 229 
uma memória visual, experiência visual e realizam uma forma de comunicação visual.

Qualquer pessoa surda, mesmo quando perde a audição (por doença ou acidente), tem uma experiência visual, todos percebem o mundo, prioritariamente, pela visão.

Literatura em língua de sinais é a literatura de pessoas surdas na língua de pessoas surdas. Isso é claro, mas além disso, é difícil definir sucintamente ou exatamente. É literatura criada em linguagem visual gestual e só existe quando alguém a realiza. Isso significa que a literatura de língua de sinais é diferente em muitos aspectos da literatura escrita com a qual a maioria de nós está familiarizada. (SuttonSpence e Kaneko 01).

A literatura escrita é uma criação estética, é uma forma de transmitir para os ouvintes a emoção da língua através das palavras, frases e sonoridade da língua; porém, os surdos, diante de um texto escrito, não sentem a mesma emoção que os ouvintes, por terem línguas e culturas diferentes. Por isso, pensamos que é importante termos as informações de uma cultura ressignificadas na outra, usando uma linguagem visual. A linguagem visual não tem limite, nós podemos criar sinais e estéticas que tenham ligação visual. Os surdos entendem e sentem emoção através dessa linguagem por sua experiência visual.

Às vezes parece ter mais em comum com a pintura, a dança ou o filme do que a literatura escrita. Embora use frequentemente o vocabulário da linguagem de sinais, ele se baseia nesses sinais para criar algo muito mais visualmente poderoso e inovador, de modo que parece ter ultrapassado os limites de uma linguagem. (Sutton-Spence e Kaneko 01). 
A linguagem visual é fundamental para o desenvolvimento cognitivo e criativo dos surdos, eles necessitam dessa linguagem e, segundo Sutton-Spence nos fala, os surdos priorizam a imagem visual. Não é necessário usar os vocábulos em Libras, pois muitas vezes estes podem ser substituídos pelo uso de classificadores ${ }^{1}$ como forma de sinais literários. Na imagem abaixo (foto 1) podemos ver o sinal de "galinha":

Foto 1: Sinal 'galinha'.

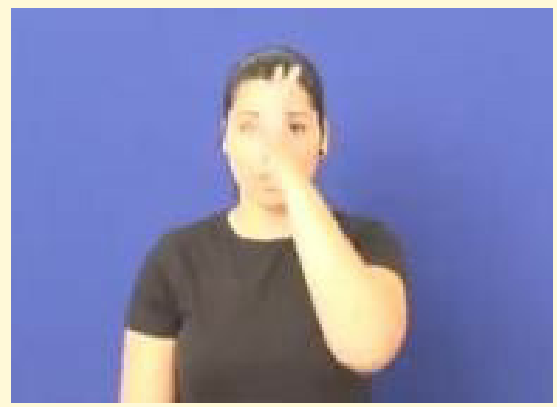

Fonte: Dicionário da Libras. V.3, 2011. http://www.acessibilidadebrasil.org.br/ libras_3/ Acesso em: 27/11/2018.

1 Este fenômeno linguístico é uma representação e/ou descrição visual de objetos, pessoas e ações de forma "icônica", embora apresente características convencionadas de forma arbitrária. Recurso linguístico bastante utilizado na Literatura pois possibilita uma maneira criativa e poética para denotar sentidos, sentimentos e descrever coisas, sem necessariamente fazer uso dos 'sinais clássicos'. Por exemplo: para falar de um gato pode-se, para além de realizar o sinal GATO, descrevê-lo denotando as suas características (tamanho, pelo formato das orelhas, comportamento, etc.).

Cad. Trad., Florianópolis, v. 41, $\mathbf{n}^{0}$ esp. 2, p. 223-249, ago/dez, 2021. 231 
Foto 2: Classificador em Libras de uma possível forma de realização do sinal 'galinha'.
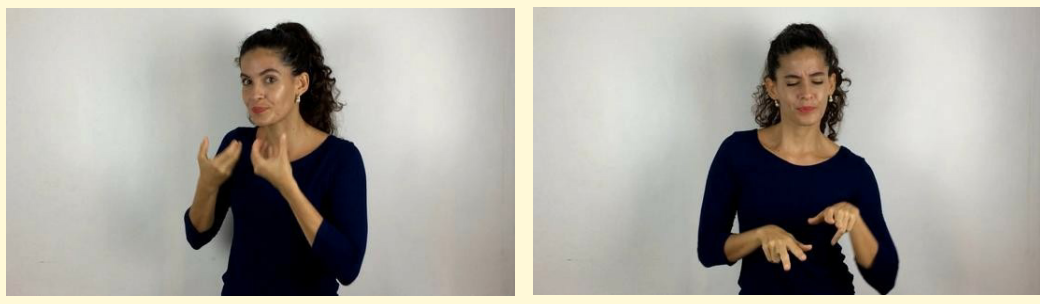

Fonte: Elaboração própria, 2018.

A imagem acima é um exemplo de 'mãos literárias', que são mãos utilizadas pelos surdos de forma estética para expressar os aspectos visuais da língua, isso é importante para transmitir as emoções, a cultura, a língua e a identidade. Esse processo ajuda as crianças no seu desenvolvimento, pois estamos falando de um mecanismo linguístico de uma língua natural e não de algo produzido mecanicamente. Segundo Mourão, “mãos literárias é a arte de sinalizar, produzir efeitos que se expressam em histórias, narrativas, contos e fábulas sinalizadas, e trazem novos sentidos" (Mourão 33).

As mãos literárias dos surdos expressam a língua de sinais e multiplicam a arte de sinalizar naturalmente, o que facilita o acesso visual da comunidade surda às artes. Temos que refletir sobre o mundo dos surdos e as possibilidades de serem seus próprios espectadores, pois existem limitações em assistir produções artísticas, teatrais ou cinematográficas que levem em consideração apenas a língua oral. Problemas podem surgir pela influência do português ou da tradução literal da literatura. É importante ter uma experiência compartilhada das mãos literárias e visualiterárias, por meio da socialização nas rodas de conversas. Mourão nos explica como produzir literatura para transformar o mundo:

Cad. Trad., Florianópolis, v. 41, $\mathbf{n}^{0}$ esp. 2, p. 223-249, ago/dez, 2021. 232 
As mãos literárias produzem ideias significativas para se transformar no palco onde os espectadores são subjetivados pela visualiterária. As mãos literárias se multiplicam na arte de sinalizar, no processo gerador significativo ao se identificarem com experiências similares, na construção da identificação de ser sujeito, na paixão de ser surdo. (Mourão 45).

\section{Tradução intermodal}

O uso e significado da palavra tradução pode ser abrangente, porém, neste artigo, podemos compreender como sendo o que se traduz entre línguas diferentes ou dentro de uma mesma língua, uma vez que "um ser humano realiza um ato de tradução, no sentido completo da palavra, quando recebe uma mensagem verbal de qualquer outro ser humano" (Steiner 71).

Todavia, quando estamos traduzindo de uma modalidade de língua para outra, temos uma tradução intermodal, que pode ser realizada do texto em português para Libras. Nesse estudo, focamos na tradução intermodal através do texto em português para Libras com adaptação em vídeo. Segala identifica o conceito da tradução intermodal e diz que esse conceito, no estudo da modalidade gestual-visual, vem se fortalecendo entre os pesquisadores:

A recodificação de uma mensagem originalmente produzida em Libras (língua gestual-visual) para o Português (língua oral-auditiva), enquadrasse no que vem sendo chamado de tradução intermodal ou, mais especificamente, Efeitos de Modalidade. Trata-se de um domínio recentemente explorado dentro dos estudos da tradução automática. (Segala 27).

Atualmente há muitos vídeos em Libras nas redes sociais. O primeiro tradutor surdo, Nelson Pimenta, que traduziu do português para vídeo em Libras, "As Fábulas de Esopo", no ano de

Cad. Trad., Florianópolis, v. 41, $\mathbf{n}^{0}$ esp. 2, p. 223-249, ago/dez, 2021. 233 
2002, hoje é um dos mais reconhecidos tradutores voluntários das redes sociais, principalmente dos sinais ilustrados ou da tradução incorporada em cena visual.

As características da tradução intermodal na literatura surda estão voltadas principalmente à expressão em língua de sinais e à compreensão histórica e literária dos surdos. As características que encontramos na literatura surda são o uso do antropomorfismo, classificadores, efeitos visual e espacial, expressões facial/corporal, incorporações, imagens visuais, movimento visual e performance. Estas são as principais características que devemos levar em consideração quando estamos usando a língua de sinais na literatura como mãos literárias.

A partir do uso desses recursos, despertamos o prazer pela própria cultura surda, compartilhamos novos materiais literários e propiciamos a aquisição da língua de sinais como primeira língua.

\section{Tradução intercultural}

Percebemos que a Tradução Intercultural sofre uma influência dos Estudos Culturais, alguns teóricos da área de Tradução Intercultural se referem a ela como sendo uma divisão de vários estudos. Sabemos que os tradutores, em contato com culturas diferentes, atuam como mediadores da tradução. Além disso, é importante lembrar que a tradução exige um profundo conhecimento das culturas alvo e fonte assim como da história dos povos em questão.

Os pesquisadores Bassnett e Trivedi, nos dizem que olhar para a tradução significa estar profundamente comprometido com questões relativas à interação cultural, relacionado também a isso, a tradução é um processo inserido em sistemas políticos e culturais de contextos históricos. Por tudo isso, o tradutor precisa estar inserido no contexto em que está atuando. Bassnett e Trivedi explicam que muitos não conseguem traduzir uma minoria linguística, porque não conseguem se aprofundar no conhecimento da cultura dessa minoria.

Cad. Trad., Florianópolis, v. 41, $\mathbf{n}^{0}$ esp. 2, p. 223-249, ago/dez, 2021. 234 
No caso específico das literaturas de minorias - como escritores chicanos, afroamericanos, entre outros - o aspecto intercultural da tradução não só é necessário, como indispensável. É bastante difícil alcançar uma boa tradução desse tipo tão especial de literatura sem se ter consciência dos aspectos culturais envolvidos. Se o tradutor não tiver consciência das marcas culturais presentes no texto em que ele está trabalhando, ele não conseguirá achar equivalentes adequados na língua alvo. (Valente e Guarischi 163).

Como sabemos, a comunidade surda é uma minoria linguística do Brasil, é importante que os tradutores reconheçam a cultura surda, convivam, compreendam o pensamento da comunidade e assimilem a empatia pelo mundo visual dos surdos, para uma melhor tradução da cultura dos surdos através da visualidade.

Sobre o contexto histórico da cultura, Strobel traça as primeiras linhas para a apresentação dos surdos como grupo cultural minoritário ou, como prefere a autora, como povo. Dessa maneira, a cultura surda é definida como:

O jeito de o sujeito surdo entender o mundo e modificá-lo a fim de torná-lo acessível e habitável, ajustando-o com suas percepções visuais, que contribuem para a definição das identidades surdas. [...] isso significa que abrange a língua, as ideias, as crenças, os costumes e os hábitos do povo surdo. (Strobel 29).

O povo surdo tem várias identidades, todas têm em comum a experiência visual. É importante ressaltar que a competência tradutória deve reconhecer as diferenças culturais. Valente explica que quando não se reconhece a cultura, é impossível ter fluência na tradução cultural.

É absolutamente fundamental que o tradutor tenha consciência do grande valor e importância da Tradução Intercultural,

Cad. Trad., Florianópolis, v. 41, $\mathbf{n}^{0}$ esp. 2, p. 223-249, ago/dez, 2021. 235 
sendo mais do que conhecedor de suas línguas de trabalho, mas também da cultura dos países falantes daquelas línguas. (Valente 26).

$\mathrm{Na}$ tradução intermodal, é necessário reconhecer a diferença cultural dos surdos e adaptar a tradução para a modalidade visual, fazendo uso pleno da língua de sinais como primeira língua e limitando a influência do português nas traduções.

\section{Metodologia}

Este artigo insere-se no rol das pesquisas qualitativas e descritivas. A pesquisa qualitativa preocupa-se com aspectos de uma realidade que não podem ser quantificados, concentrando-se na compreensão e explicação de fenômenos sociais. Entre as características dessa pesquisa estão: objetivar, descrever, compreender e explicar determinado fenômeno. De acordo com Gil, as pesquisas descritivas "têm como objetivo primordial a descrição de determinada população ou fenômeno ou, então, o estabelecimento de relações entre variáveis" (Gil 42). Este trabalho teve como um de seus objetivos: descrever e compreender a tradução português-Libras, no tocante à Literatura Surda Infantil. O propósito de analisar a produção literária traduzida em Libras é focar na estética da contação. O objetivo da análise qualitativa do uso da língua de sinais é verificar a história contada e saber quais as suas características, analisando o uso da língua de sinais e a clareza de sua expressão.

Quanto à análise utilizamos o método de procedimento: estudo de caso. Gil classifica o estudo de caso como aquele que se caracteriza pelo estudo profundo e exaustivo de um ou de poucos objetos, de maneira que permita o seu amplo e detalhado conhecimento.

Essa pesquisa surgiu a partir de um trabalho desenvolvido na disciplina de Prática da Tradução II, no curso de Mestrado do Programa de Pós-Graduação em Estudos da Tradução-UFC, por duas das autoras deste artigo. Foram estudados, na disciplina, vá-

Cad. Trad., Florianópolis, v. 41, $\mathbf{n}^{0}$ esp. 2, p. 223-249, ago/dez, 2021. 236 
rios vídeos traduzidos em Libras e encontrados alguns problemas na tradução de alguns contos infantis, voltados a uma faixa etária de dois a onze anos de idade. Nesse percurso, foi encontrado o trabalho de uma blogueira surda que criou o blog denominado "Mãos aventureiras", ela é muito conhecida pela comunidade surda, por compartilhar várias traduções em Libras² .

Como dissemos, a literatura surda é categorizada em três eixos: tradução, criação e adaptação. Nós trabalhamos com a tradução e escolhemos a literatura infantil por existirem vários livros publicados e traduzidos para Libras. Para a nossa pesquisa, selecionamos, no Youtube, o vídeo em Libras traduzido do livro "O Sanduíche da Maricota" 3 , pela blogueira surda ${ }^{4}$.

Inicialmente, assistimos ao vídeo, observando e analisando os sinais utilizados na contação da história. Apesar do excelente trabalho realizado pela tradutora, principalmente quanto a divulgação de contos infantis, avaliamos que, no conto analisado, alguns sinais utilizados fugiam a estética da contação de histórias; para além disso, encontramos exemplos de omissões, tradução literal, pouco uso de classificadores, recurso importantíssimo para a contação de histórias em sinais e para a literatura surda. A partir daí, fizemos sugestões de alterações do que avaliamos não estar adequado às características da contação de histórias em sinais. Em um segundo momento, realizamos a tradução dessa mesma história, utilizando os recursos disponíveis na língua e levando em consideração os aspectos de uma tradução intermodal. Posteriormente, fizemos uma comparação entre os dois vídeos traduzidos em Libras.

2 Ela compartilha vídeos literários nas redes sociais, isso é importante, pois incentiva as crianças surdas a conhecerem histórias diferentes.

${ }^{3}$ Este conto foi escrito por Avelino Guedes. Literatura voltada para crianças a partir de seis anos. A história versa sobre a preparação, pela galinha Maricota, de um sanduíche. Porém, antes de concluir o processo de preparação do lanche, vários animais passam a "dar pitaco" sobre como ela deveria prepará-lo.

${ }^{4}$ A blogueira e tradutora do conto é a, também professora e pesquisadora da área de Literatura Surda, Carolina Hessel. Na tradução do livro para Libras, não foi especificada a faixa etária a qual se destina a tradução. Essa seria uma informação importante.

Cad. Trad., Florianópolis, v. 41, $\mathrm{n}^{0}$ esp. 2, p. 223-249, ago/dez, 2021. 237 
Neste artigo, trazemos um recorte da comparação realizada e indicamos as alterações realizadas na tradução.

\section{Análise e discussão}

A publicação de histórias para as crianças surdas oportuniza e facilita o acesso à língua de sinais, através da literatura a criança tem a chance de fortalecer a sua língua adquirindo novos vocabulários e expandindo a sua compreensão de mundo, mas, ainda assim, encontramos, nas publicações, alguns pontos que consideramos negativos.

Os problemas que encontramos nas traduções dos textos literários devem nos permitir criar outras formas de produção dessas histórias, outras formas que possibilitem as contações serem mais atrativas e trazerem mais emoções ao público infantil. Infelizmente, a maioria dos tradutores utiliza vocábulos em sinais com menos ação e por isso, algumas vezes as crianças surdas não compreendem o contexto da história, exatamente pela falta do uso de classificadores, de verbos de ação, do uso inadequado da estrutura e da gramática da língua de sinais para expressar emoções.

Encontramos algumas desvantagens na tradução apresentada pela blogueira, ela considerou como importante traduzir mais os sinais, numa tradução literal, e considerar pouco a adaptação de uma tradução intermodal. Como a blogueira foca nos contos para crianças, acreditamos que deveria investir mais no uso de expressões faciais, no uso da língua considerando o movimento visual; o que preocupa nesse modelo de tradução apresentado pela blogueira, é a imagem de língua repassada às crianças surdas. Ao se espelharem nas imagens do tradutor, observamos, por exemplo, que as crianças não utilizam classificadores. Desse modo, é importante o tradutor estar atento à incorporação dos recursos visuais da língua, pois muitas crianças precisam desse recurso para compreender o que se sinaliza.

É importante incentivar as crianças surdas a conhecerem as histórias e expressarem o seu imaginário, ainda temos poucas obras publicadas em Libras. Geralmente, as crianças têm pouco conhe-

Cad. Trad., Florianópolis, v. 41, $\mathrm{n}^{0}$ esp. 2, p. 223-249, ago/dez, 2021. 238 
cimento do uso mais efetivo e extensivo do vocabulário em língua de sinais, a literatura surda e a literatura traduzida (tradução intermodal) são caminhos que propiciam à criança surda o acesso a sua língua genuína. É importante ressaltar a valorização visual dos surdos e trazer para a interpretação intermodal o efetivo uso da língua de sinais e seus recursos.

Temos abaixo alguns prints ${ }^{5}$ do vídeo em Libras da história "O Sanduíche da Maricota”, na coluna da esquerda temos a sinalização do Youtube, na coluna da direita temos as nossas sugestões de alterações, considerando os classificadores e expressões faciais/corporais:

Tabela 1: Elaboração própria, 2018.

\begin{tabular}{|l|l|l|}
\hline $\mathbf{n}^{\circ}$ & Vídeo no Youtube & Vídeo com sugestões \\
\hline 1 & & \\
\hline
\end{tabular}

${ }^{5}$ Não buscamos a autorização da blogueira para a utilização de sua imagem. Dessa forma, embora o Youtube seja um site de domínio público, decidimos reproduzir as imagens do Youtube com uma sinalizante participante deste estudo.

Cad. Trad., Florianópolis, v. 41, $\mathbf{n}^{0}$ esp. 2, p. 223-249, ago/dez, 2021. 239 


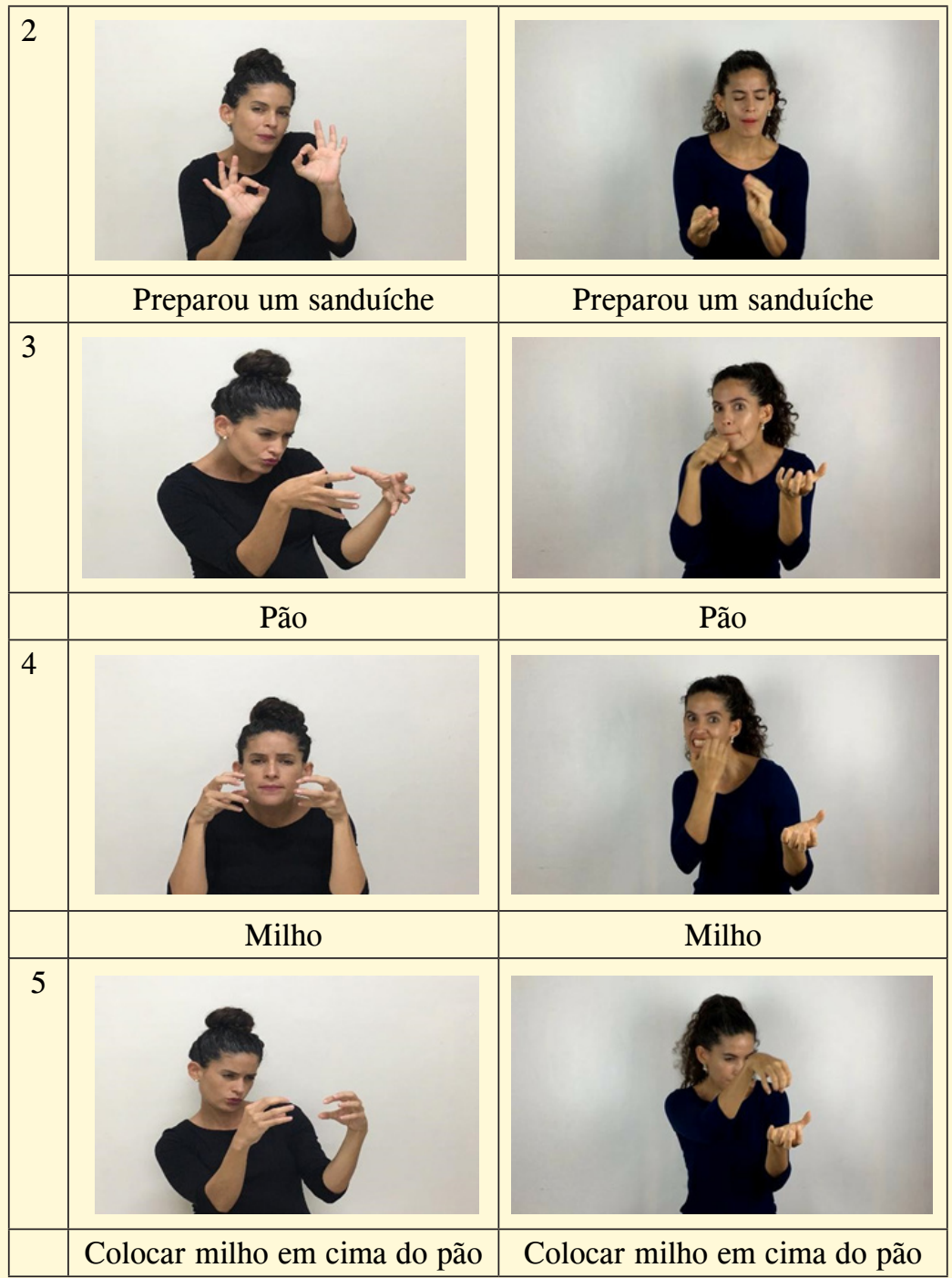

Cad. Trad., Florianópolis, v. 41, $\mathbf{n}^{0}$ esp. 2, p. 223-249, ago/dez, 2021. 240 


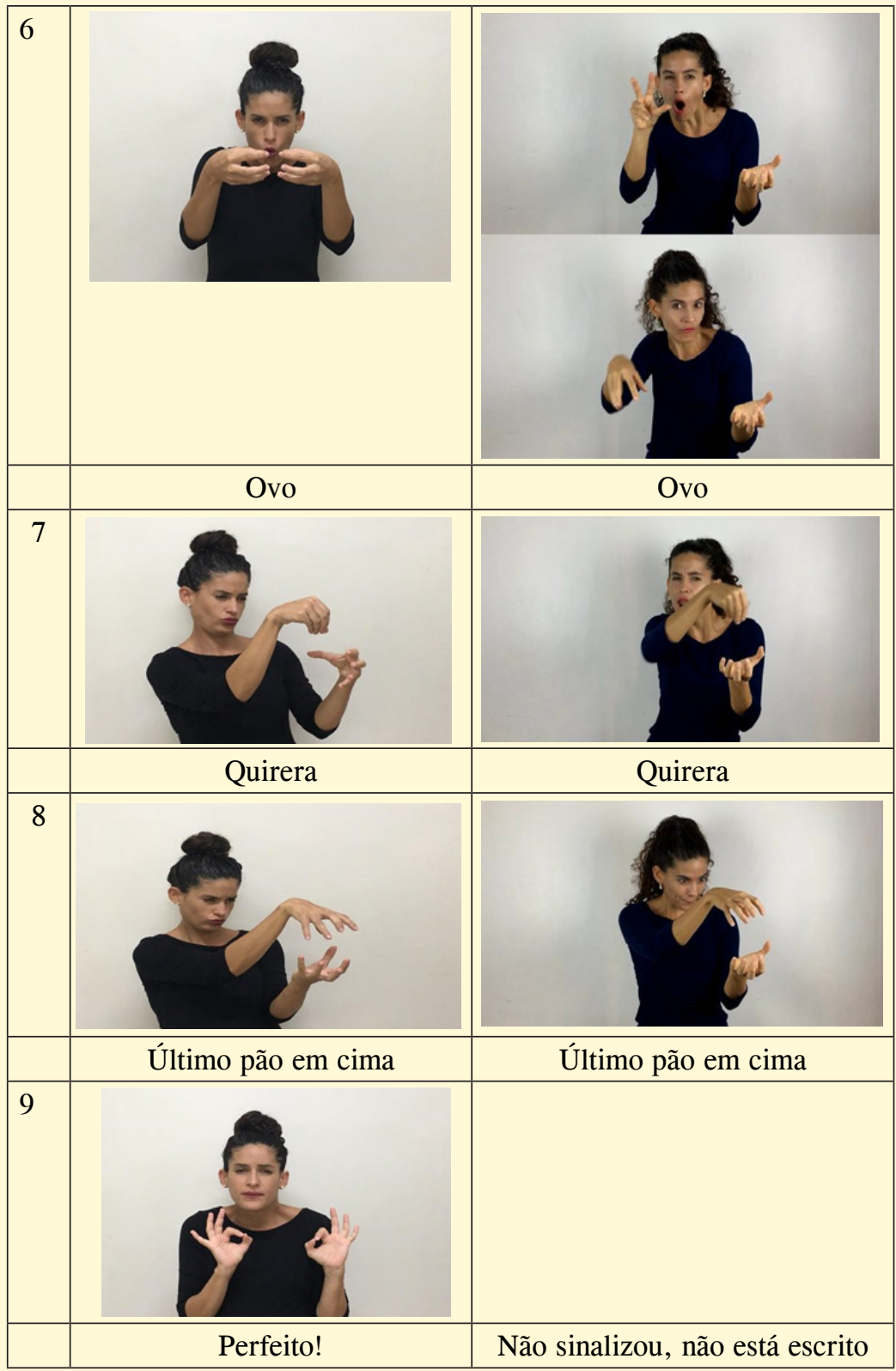

Cad. Trad., Florianópolis, v. 41, $\mathbf{n}^{0}$ esp. 2, p. 223-249, ago/dez, 2021. 241 


\begin{tabular}{|c|c|c|}
\hline 10 & & 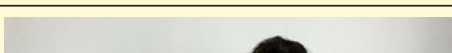 \\
\hline & $\begin{array}{l}\text { Quando ia comer, a campainha } \\
\text { tocou... }\end{array}$ & O barulho da campainha \\
\hline 11 & & 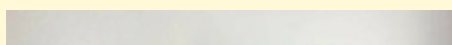 \\
\hline & O barulho da campainha & $\begin{array}{l}\text { Quando ia comer, a campainha } \\
\text { tocou... }\end{array}$ \\
\hline 12 & & \\
\hline & A galinha anda e... & A galinha anda e... \\
\hline 13 & & \\
\hline & Abriu a porta. & Abriu a porta. \\
\hline
\end{tabular}

$\mathrm{Na}$ análise percebemos que alguns sinais utilizados são dialetos, a blogueira e a sinalizante do nosso estudo são de estados dife- 
rentes. Vemos, por exemplo, sinalizações diferentes para Galinha Maricota, na linha 1, a blogueira sinalizou "a galinha", mas não se utilizou da classificação corporal; na outra sinalização temos um sinal com uso de classificador, mostrando o jeito da galinha andar.

Nas imagens 3 a 8, observamos a blogueira sinalizar a preparação do sanduíche, realizando uma sequência de sinais, porém ela não manteve o pão colocado no espaço destinado a realização da ação, o que poderia ilustrar todo um quadro visual do preparo do sanduíche; na outra sinalização, observamos exatamente o contrário, a sinalizante 'segura' o pão durante toda a ação de preparação do sanduíche, o que permite uma visualização e entendimento da cena. Na imagem 9, a blogueira acrescentou um sinal que não está escrito na história em português, isso pode ter sido uma estratégia de tradução. Nas imagens 10 e 11, a blogueira inicia a sinalização olhando para trás na intenção de 'mostrar' o toque da campainha, mas isso não fica claro na sinalização, ela poderia ter iniciado explicitando o toque da campainha, como aparece na imagem sugerida por nós, e depois daria sequência a sinalização da história.

$\mathrm{Na}$ imagem 12, percebe-se que o jeito da galinha andar foi sinalizado pela blogueira de forma literal, fazendo uso do sinal 'dois dedos andando' como se fosse o sinal de uma pessoa andando, já a outra sinalizante incorporou o jeito de andar da galinha, utilizando um classificador para designar o seu pé e o seu jeito de andar.

Seguem mais comparações dos vídeos em Libras realizados pelas tradutoras. Tabela 2: Elaboração própria, 2018.

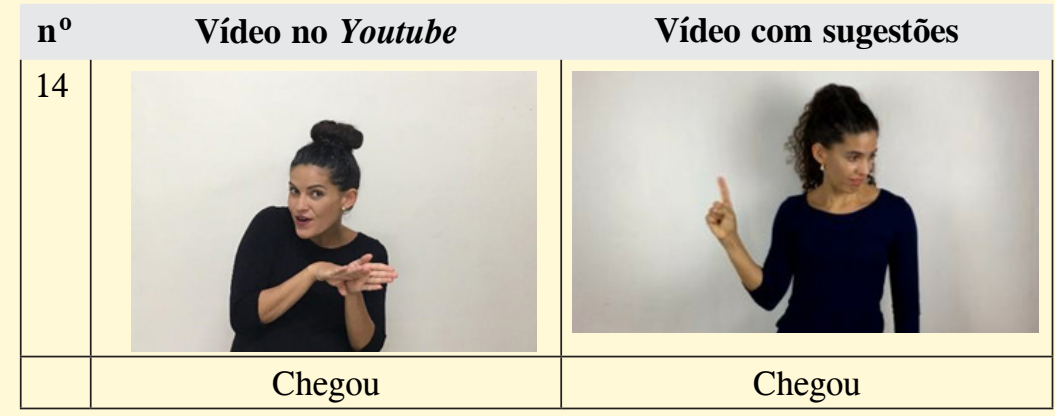

Cad. Trad., Florianópolis, v. 41, $\mathbf{n}^{0}$ esp. 2, p. 223-249, ago/dez, 2021. 243 


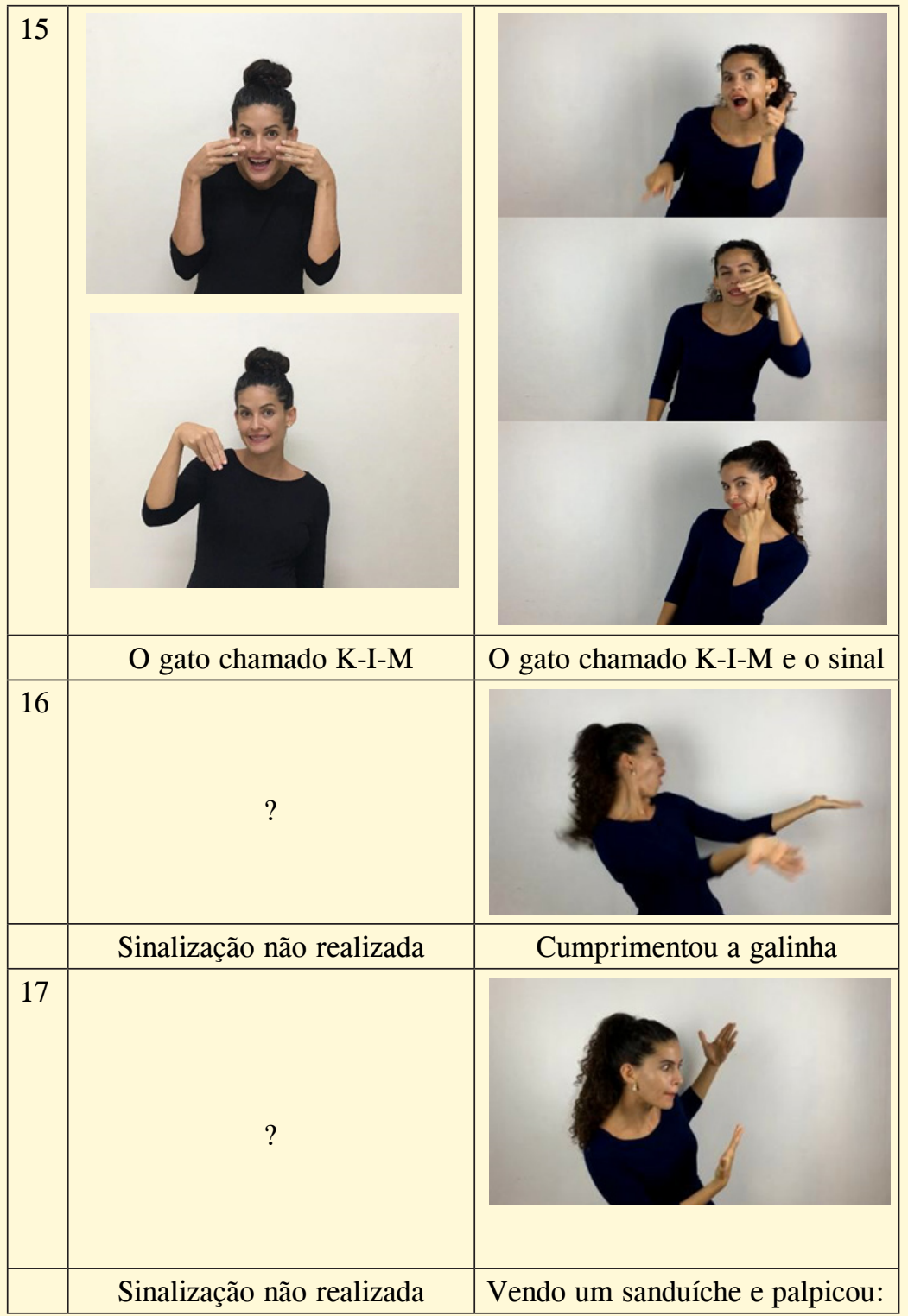

Cad. Trad., Florianópolis, v. 41, $\mathrm{n}^{0}$ esp. 2, p. 223-249, ago/dez, 2021. 244 


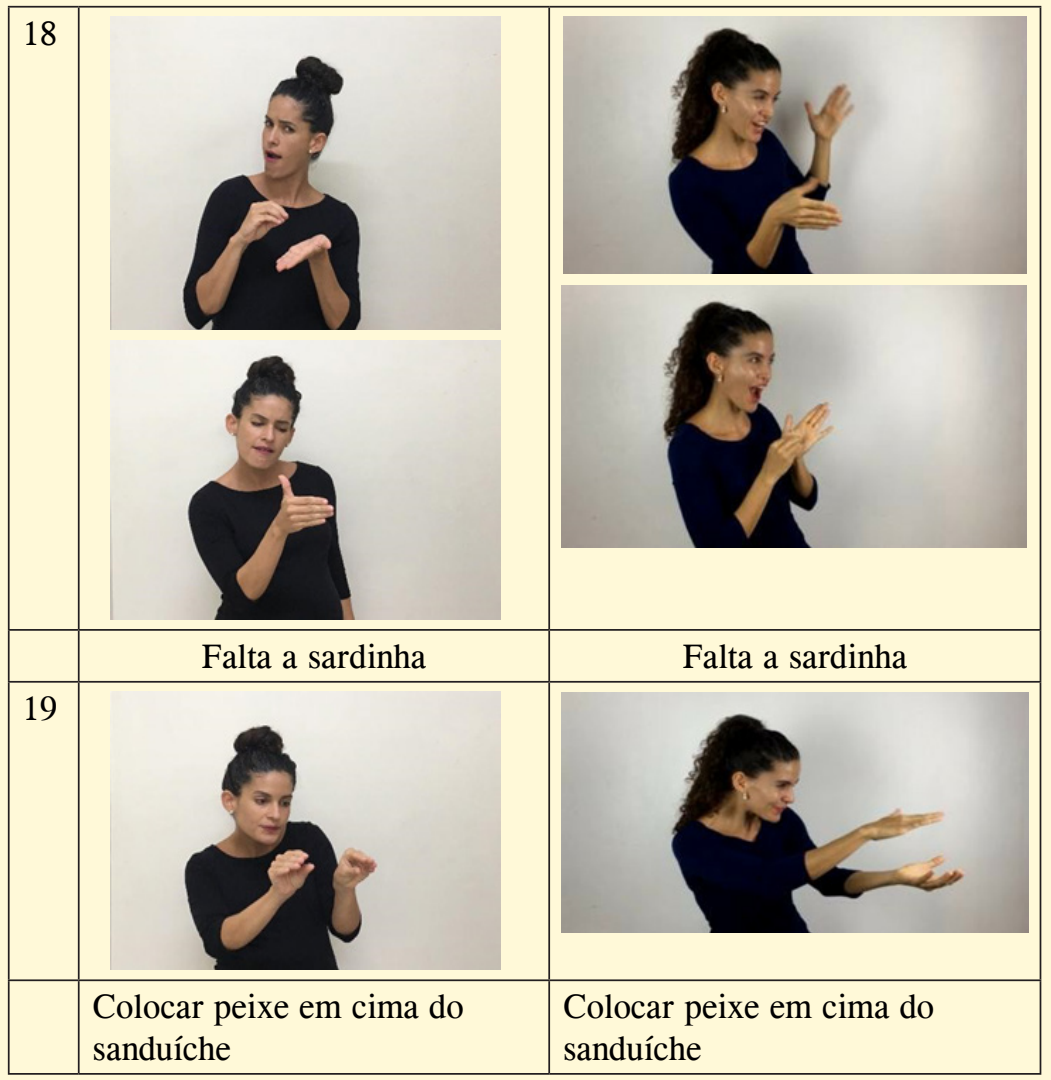

Na imagem 14, a blogueira não incorporou a chegada de um gato, apenas sinalizou o verbo chegar. Na imagem 15, ambas as sinalizadoras realizaram o sinal de gato, no entanto, há uma variação linguística na realização do sinal. As duas tradutoras soletraram o nome do gato "Kim", mas, apenas a sinalizante colaboradora deste trabalho fechou o quadro dando um sinal para o gato. É importante dar um sinal próprio ao animal, pois as crianças ainda não sabem soletrar, é importante facilitar a sinalização para a identificação do animal e o entendimento da história. Deve-se pensar na estratégia da soletração após a alfabetização da criança, porém, a blogueira

Cad. Trad., Florianópolis, v. 41, $\mathrm{n}^{0}$ esp. 2, p. 223-249, ago/dez, 2021. 245 
não informa, em sua tradução, qual é a idade a qual se destina a tradução realizada. A faixa etária do livro em português é destinada a crianças de 6 a 7 anos.

Nas imagens 16 e 17 há uma lacuna na sinalização da blogueira, ela não realizou os sinais, não seguiu a sequência do livro, ilustrando uma omissão na tradução. Na imagem 19, como aconteceu anteriormente, a blogueira não 'segurou' o pão na situação de enunciação para colocar o peixe em cima.

\section{Conclusão}

As crianças surdas que não têm acesso à Libras e aos seus aspectos corporais como primeira língua terão dificuldades de compreensão, elas precisam ter acesso a língua de sinais e a todos os seus recursos visuais e linguísticos para compreenderem as histórias contadas. A criança surda só terá acesso a sua língua materna através do uso da modalidade de língua gestual-visual, uma forma de incentivar esse acesso é através da contação de histórias infantis.

Existem poucas pesquisas sobre tradução literária em Libras. É necessário ter mais vídeos, livros didáticos, cursos de tradução literária e novas estratégias para produzir novos conhecimentos sobre o processo desse tipo de tradução. Esperamos que os profissionais que trabalham com a tradução literária possam realizar a tradução intermodal para crianças surdas utilizando os recursos visuais da língua de maneira que oportunize a criança surda a despertar o seu mundo imaginário literário.

Como o trabalho com a tradução de histórias literárias não é um trabalho fácil e desenvolvê-lo sozinho pode significar uma não percepção do que se está desenvolvendo, é importante sempre que esse tipo de tradução seja realizado por no mínimo duas pessoas, para que haja sempre uma avaliação e correção do que se é produzido, antes dos compartilhamentos dos vídeos. Embora essa seja uma prática das editoras, os tradutores de vídeos livres que circulam na internet, nem sempre se utilizam dessa prática de tradução. A prá-

Cad. Trad., Florianópolis, v. 41, $\mathrm{n}^{0}$ esp. 2, p. 223-249, ago/dez, 2021. 246 
tica do trabalho em parceria e a utilização da revisão da tradução evitaria um prejuízo para as crianças surdas ao acompanharem as histórias e teriam um ganho ao incorporarem o modelo de sinalização do tradutor.

Os profissionais da tradução devem conhecer o estudo da estrutura linguística da Libras, do uso de classificadores, da incorporação, da cultura surda, do antropomorfismo, das expressões facial/ corporal. É possível ter uma boa formação profissional específica para profissionais que queiram adentrar a área da literatura e/ou de artes. Não devemos esquecer a importância de incorporar a cultura surda a tudo isso. Acreditamos que outros estudos voltados a esse tipo de tradução virão e as produções culturais atenderão às características da tradução intermodal para os surdos, pois sem esses cuidados a comunidade surda tem muito a perder.

\section{Referências}

Bassnett, Susan; Trivedi, Harish. (eds.) Post-colonial Translation: theory and practice. London: Routledge, 1999.

Gil, Antonio Carlos. Métodos e técnicas de pesquisa social. 5. ed. São Paulo: Atlas, 1999.

Gil, Antonio Carlos. Como elaborar projetos de pesquisa. 4. ed. São Paulo: Atlas, 2002.

Karnopp, Lodenir Becker; Machado, Rodrigo Nogueira. Literatura Surda: ver histórias em língua de sinais. In: 2 Seminário Brasileiro de Estudos Culturais em Educação, 2006, Canoas. 2 SBECE. Canoas: ULBRA, 2006.

Cad. Trad., Florianópolis, v. 41, $\mathbf{n}^{0}$ esp. 2, p. 223-249, ago/dez, 2021. 247 
Karnopp, Lodenir Becker; Silveira, Carolina Hessel. Metodologia da Literatura Surda. Curso de Letras Libras. CCE/UFSC - Florianópolis: 2009.

Morgado, Marta. Literatura em Língua Gestual. In: Karnopp, Lodenir Becker; Klein, Madalena; Lunardi-Lazzarin, Márcia (orgs.). Cultura Surda na contemporaneidade: negociações, intercorrências e provocações. Canoas: Ed. ULBRA, 2011.

Mourão, Cláudio Henrique Nunes. Literatura Surda: experiência das mãos literárias. Dissertação (doutorado da tradução) Programa de pós-graduação da educação, UFRGS: Porto Alegre, 2016.

Quadros, Ronice Muller de; Karnopp, Lodenir Becker. Língua de sinais brasileira: estudos linguísticos. Porto Alegre: ARTMED, 2007.

Rosa, Fabiano Souto. Literatura surda: o que sinalizam professores surdos sobre livros digitais em Língua Brasileira de Sinais - Libras. Dissertação (Mestrado em Educação) - Faculdade de Educação, Universidade Federal de Pelotas, 2011.

Segala, Rimar Ramalho. Tradução intermodal, intersemiótica e interlinguística de textos escritos em Português para a Libras oral. Dissertação (mestrado da tradução) Pós-graduação do estudo da tradução, PGET/UFSC: Florianópolis, 2010.

Steiner, George. Depois de Babel: questões de linguagem e tradução. Curitiba: UFPR, 2005.

Strobel, Karin. As imagens do outro sobre a cultura surda. Florianópolis: Ed. UFSC, 2013.

Sutton-Spence, Rachel; Kaneko, Michiko. Introducing Sign Language Literature: Folklore and Creativity. Palgrave Macmillan. Edição do Kindle, 2016.

Valente, Marcela Iochem. A tradução para legendagem e seus submercados. In: Jornada de Estudos da linguagem 3, 2006, Rio de Janeiro. Caderno de Resumos. Rio de Janeiro: UERJ, 2006. 
Valente, Marcela Iochem; Guarischi, Rafael Machado. A tradução intercultural e seus desafios: uma questão para os estudos da linguagem ou para os estudos culturais. Revista ALPHA. Patos de Minas: UNIPAM, (11): 161-166, ago. 2010. Disponível em: alpha.unipam.edu.br Acesso em: 27 de novembro de 2018.

Lyvia de Araújo Cruz. E-mail: lyviaaraujo@yahoo.com.br. https://orcid.org/00000002-0531-5074.

Michelle Arrais Guedes. E-mail: michellearraes@gmail.com. https://orcid. org/0000-0001-7305-9669.

Andréa Michiles Lemos. E-mail: andrea.lemos@ifce.edu.br. https://orcid. org/0000-0002-7194-0054.

Cad. Trad., Florianópolis, v. 41, $\mathbf{n}^{0}$ esp. 2, p. 223-249, ago/dez, 2021. 249 